\title{
Differences in UGT1A1, UGT1A7, and UGT1A9 Polymorphisms between Uzbek and Japanese Populations
}

\author{
Hiromichi Maeda $\cdot$ Shoichi Hazama $\cdot$ Abdiev Shavkat $\cdot$ Ken Okamoto $\cdot$ \\ Koji Oba $\cdot$ Junichi Sakamoto $\cdot$ Kenichi Takahashi $\cdot$ Masaki Oka $\cdot$ Daisuke Nakamura \\ Ryouichi Tsunedomi $\cdot$ Naoko Okayama $\cdot$ Hideyuki Mishima $\cdot$ Michiya Kobayashi
}

Published online: 23 January 2014

(C) The Author(s) 2014. This article is published with open access at Springerlink.com

\begin{abstract}
Background and Objectives Uridine-diphosphate glucuronosyltransferase 1A (UGT1A) is a key enzyme involved in irinotecan metabolism, and polymorphisms in the UGTIA gene are associated with irinotecan-induced toxicity. The aim of this study was to elucidate the allele frequencies of UGTIA polymorphisms in healthy Uzbek volunteers, and to compare them with those of the Japanese population.

Method A total of 97 healthy volunteers from Uzbekistan were enrolled and blood samples were collected from each participant. Genotyping analysis was performed by fragment size analysis for $U G T 1 A 1 * 28$, direct sequencing for $U G T I A 7 * 3$ and $U G T 1 A 9 * 22$, and TaqMan assays for $U G T 1 A 1 * 93, U G T 1 A 1 * 6, U G T 1 A 1 * 27$, $U G T 1 A 1 * 60$, and $U G T 1 A 7 * 12$. The frequencies of polymorphisms were compared with the Japanese
\end{abstract}

H. Maeda $\cdot$ K. Okamoto $\cdot$ M. Kobayashi $(\square)$

Department of Human Health and Medical Sciences, Kochi

Medical School, Kohasu, Oko-cho, Nankoku 783-8505, Japan

e-mail: kobayasm@kochi-u.ac.jp

S. Hazama $\cdot$ M. Oka $\cdot$ R. Tsunedomi

Department of Digestive Surgery and Surgical Oncology

(Surgery II), Yamaguchi University Graduate School of

Medicine, Ube 755-8505, Japan

A. Shavkat

Nozaki Tokushukai Hospital, Daito 574-0074, Japan

K. Oba

Translational Research and Clinical Trial Center, Hokkaido

University Hospital, Sapporo 060-8638, Japan

J. Sakamoto

Tokai Central Hospital, Kakamigahara 504-8601, Japan population by using the data previously reported from our study group.

Results When the Uzbek and Japanese populations were compared, heterozygotes or homozygotes for $U G T 1 A 1 * 28$, $U G T I A 1 * 60$, and $U G T 1 A 1 * 93$ were significantly more frequent in the Uzbek population $(P<0.01)$. The rate of $U G T 1 A 7 * 12$ was not significantly different between the two populations, whereas UGTIAI*6 and UGT1A9*22 were significantly less frequent in the Uzbek population $(P<0.05) . U G T 1 A 7 * 1$ were less prevalent in the Uzbek population than in the Japanese population $(P<0.01)$.

Conclusion The Uzbek population has different frequencies of polymorphisms in UGTIA genes compared with the Japanese population. A comprehensive study of the influence of UGTIA1 polymorphisms on the risk of irinotecan-induced toxicity is necessary for optimal use of irinotecan treatment.

\author{
K. Takahashi \\ Department of Surgery, Aomori Prefectural Central Hospital, \\ Aomori 030-8553, Japan \\ D. Nakamura \\ Chikamori Hospital, Kochi 780-8522, Japan \\ N. Okayama \\ Department of Oncology and Laboratory Medicine, Yamaguchi \\ University Graduate School of Medicine, Ube 755-8505, Japan \\ H. Mishima \\ Department of Surgery, Osaka National Hospital, \\ Osaka 565-0871, Japan
}




\section{Introduction}

Irinotecan in combination with fluorouracil and leucovorin prolongs the progression-free survival and overall survival of patients with metastatic colorectal cancer compared with fluorouracil and leucovorin alone. However, grade 3/4 diarrhea and neutropenia can occur during the course of the treatment, jeopardizing approximately $20-25$ and $25-55 \%$ of patients, respectively $[1,2]$. The toxicity of irinotecan is influenced by several non-genetic factors [3, 4]. A number of recent studies have found a strong relationship between the adverse effects of irinotecan-based treatment and polymorphisms of the uridine-diphosphate glucuronosyltransferase 1A (UGT1A) gene, which encodes a crucial enzyme in irinotecan metabolism [5-13].

Administered irinotecan is activated and transformed through hydrolysis into 7-ethyl-10-hydroxycamptothecin (SN-38), which is a potent inhibitor of topoisomerase I and is the metabolite responsible for adverse reactions to irinotecan-based treatment [14]. SN-38 is then converted into an inactive form, 10-O-glucuronyl-SN-38 (SN-38G), by various UGT1A isoforms including UGT1A1, 1A6, 1A7, $1 \mathrm{~A} 8,1 \mathrm{~A} 9$, and $1 \mathrm{~A} 10$ [15-17]. Therefore, irinotecaninduced toxicities could be due to a reduced glucuronidation rate of $\mathrm{SN}-38$ caused by genetic variants of UGTIA. One of the representative polymorphisms that strongly influences irinotecan clearance is $U G T 1 A 1 * 28$, which has $(\mathrm{TA})_{7}$ in the promoter region instead of $(\mathrm{TA})_{6}$ as in $U G T 1 A 1 * 1$ [18]. Individuals with $U G T 1 A 1 * 28$ demonstrate reduced irinotecan clearance $[10,12]$ due to reduced transcriptional activity of UGTIAI [18]. The UGTIAI $* 28$ polymorphism may increase the clinical risk of severe irinotecan-induced toxicity in colorectal cancer patients [5, 6]. In contrast to the effect of $U G T 1 A 1 * 28$ on transcriptional efficacy, $U G T 1 A 1 * 6$ has $\mathrm{G}$ replaced by A at position +211 relative to the UGT1Al transcription start site, which results in decreased irinotecan metabolism [19].

Several polymorphisms, especially UGT1A1, 1A7, and $1 A 9$, are associated with an alteration in irinotecan metabolism and are receiving increasing attention in clinical settings $[8,20]$, but only UGTIAI $* 28$ and UGTIAI $* 6$ have been extensively studied. We recently examined irinotecan metabolism-related UGTIA polymorphisms and reported their frequency in three geographically different regions in Japan [21]. We consider that studying the interethnic diversity of these polymorphisms will lead to an understanding of the inconsistent drug responses observed between different populations, and will ultimately help establish the best strategies for application of new drugs in these populations. In this context, this study was designed to determine the allele frequency of $U G T 1 A 1 * 27$, UGTIA1*60, UGT1A1*93, UGT1A7*2 (N129K), UGT1A7*3 (co-occurrence of $\mathrm{N} 129 \mathrm{~K}$ and W208R),
$U G T 1 A 7 * 12$, and $U G T 1 A 9 * 22$ as well as $U G T 1 A 1 * 28$ and $U G T 1 A 1 * 6$ in healthy volunteers of the Republic of Uzbekistan, a country located between East Asia and Europe (Table 1; Fig. 1).

\section{Methods}

\subsection{Subjects}

This study was approved by the ethics committee of Yamaguchi University, and written informed consent was obtained from all participants. We recruited 97 volunteers from Uzbekistan. A $7 \mathrm{ml}$ sample of peripheral blood was collected from each individual and stored in ethylenediaminetetraacetic acid (EDTA). The 150 healthy Japanese volunteers were from three districts in Japan, and we have investigated and reported on their polymorphisms previously [21].

\subsection{Genotyping}

Genomic DNA from peripheral blood anti-coagulated with EDTA was extracted by using the conventional $\mathrm{NaI}$ method. UGTIAI $* 28$ was identified using fragment size analysis, and $U G T 1 A 7 * 3$ and $U G T 1 A 9 * 22$ were detected using direct sequencing. A TaqMan assay was performed for the identification of UGTIAI*93, UGTIAI*6, $U G T 1 A 1 * 27, U G T 1 A 1 * 60$, and $U G T 1 A 7 * 12$. Primers and probes used in the study are listed in Table 1.

For fragment size analysis, polymerase chain reaction (PCR) reactions using $800 \mathrm{ng}$ of template DNA were performed according to the manufacturer's instructions (Ex Taq; Takara, Tokyo, Japan). The PCR products of TA6 (6 TA repeats; 94 bp) and TA7 (7 TA repeats; 96 bp) were mixed with Hi-Di formamide and the internal size standard (GeneScan LIZ-500, Applied Biosystems, CA, USA) at a ratio of 1:10 (v/v). After electrophoresis in the ABI Prism 3100 Genetic Analyzer (Applied Biosystems), fragment sizes were compared with the internal size standard and determined by the local Southern algorithm and by GeneMapper software version 3.5 (Applied Biosystems).

For direct sequencing, PCR was conducted using the Gene Amp PCR System PC808 (ASTEC, Tokyo, Japan) with Ex Taq polymerase. Purification of PCR products was performed with ExoSAP-IT (Amersham Bioscience, Tokyo, Japan) for $20 \mathrm{~min}$ at $37^{\circ} \mathrm{C}$ followed by $20 \mathrm{~min}$ at $80^{\circ} \mathrm{C}$. Sequencing reactions were conducted with a BigDye Terminator Cycle Sequencing Kit (Applied Biosystems, Tokyo, Japan), and, after the reaction products were purified with ethanol, analysis was performed using an ABI 3100-Avant Genetic Analyzer (Applied Biosystems). 
Table 1 Primers and probes for genotyping

\begin{tabular}{|c|c|c|c|c|}
\hline Polymorphism & Position & $\mathrm{WT}>$ variant & & Primer or Probe \\
\hline$U G T 1 A 1 * 6$ & 211 & $\mathrm{G}>\mathrm{A}$ & & C 55971520 \\
\hline$U G T 1 A 1 * 27$ & 686 & $\mathrm{C}>\mathrm{A}$ & & C 230759820 \\
\hline$U G T 1 A 1 * 28$ & TATA box & TA6>TA7 & $\begin{array}{l}\text { F-FAM } \\
\mathrm{R}\end{array}$ & $\begin{array}{l}5^{\prime} \text {-gtgacacagtcaaacattaacttgt- } 3^{\prime} \\
5^{\prime} \text {-gcctttgctcctgccagaggtt- } 3^{\prime}\end{array}$ \\
\hline$U G T 1 A 1 * 60$ & -3279 & $\mathrm{~T}>\mathrm{G}$ & & C 143213410 \\
\hline$U G T 1 A 1 * 93$ & -3156 & $\mathrm{G}>\mathrm{A}$ & $\begin{array}{l}\text { F } \\
\text { R } \\
\text { FAM } \\
\text { VIC }\end{array}$ & $\begin{array}{l}5^{\prime} \text {-acttaacattgcagcacagg- } 3^{\prime} \\
5^{\prime} \text {-atgggcaaaagcttgaact- } 3^{\prime} \\
5^{\prime} \text {-cctgtccaagctca-3' } \\
5^{\prime} \text {-cacctgtctaagctca-3' }\end{array}$ \\
\hline$U G T 1 A 7 * 2(\mathrm{~N} 129 \mathrm{~K})$ UGT1A7*3 (W208R) & $\begin{array}{l}387 \\
622\end{array}$ & $\begin{array}{l}\mathrm{T}>\mathrm{G} \\
\mathrm{T}>\mathrm{C}\end{array}$ & $\begin{array}{l}\mathrm{F} \\
\mathrm{R}\end{array}$ & $\begin{array}{l}5^{\prime} \text {-tacactctggaggatcagga-3' } \\
5^{\prime} \text {-tattgggcatcacgggtttg- } 3^{\prime}\end{array}$ \\
\hline$U G T 1 A 7 * 12$ & -57 & $\mathrm{~T}>\mathrm{G}$ & & C 28726510 \\
\hline UGT1A9* 22 & -188 & $\mathrm{~T} 9>\mathrm{T} 10$ & $\begin{array}{l}\mathrm{F} \\
\mathrm{R}\end{array}$ & $\begin{array}{l}5^{\prime} \text {-acttaacattgcagcacagg- } 3^{\prime} \\
5^{\prime} \text {-atgggcaaaagccttgaact- } 3^{\prime}\end{array}$ \\
\hline
\end{tabular}

Nucleotide positions are relative to the transcription start site

Transposition of $\mathrm{T}$ to $\mathrm{G}$ at position 387 (or N129K) is termed $U G T 1 A 7 * 2$. Transposition of $\mathrm{T}$ to $\mathrm{C}$ at position 622 is termed W208R, and cooccurrence of $\mathrm{N} 129 \mathrm{~K}$ and W208R is termed UGT1A7*3

TA6 6 TA repeats, TA7 7 TA repeats, F-FAM forward primer-labeled reporter 1 probe, $F$ forward primer, $R$ reverse primer, FAM reporter 1 probe, $V I C$ reporter 2 probe, $W T$ wild type

As described in Table 1, the transposition of $\mathrm{T}$ to $\mathrm{G}$ at position 387 (or N129K), C to A at position 391, and G to A at position 392 are termed UGT1A7*2. These three polymorphisms are genetically linked, and only $\mathrm{N} 129 \mathrm{~K}$ is described in this manuscript. The transposition of $\mathrm{T}$ to $\mathrm{C}$ at position 622 is termed W208R, and co-occurrence of $\mathrm{N} 129 \mathrm{~K}$ and W208R is termed UGT1A7*3, whereas the occurrence of W208 alone is termed UGT1A7*4. Thus, in the case of heterozygous N129K and heterozygous W208R in the same individual, the possible genotypes are $U G T 1 A 7 * 1 / * 3$ and $* 2 / * 4$. However, because UGT1A7*4 is known to be quite rare in non-Uzbek populations [9, 17], the statistical analysis was performed on the assumption that all the genotypes were $U G T 1 A 7 * 1 / * 3$.

For TaqMan assays for $U G T 1 A 1 * 93$, forward and reverse PCR primers and TaqMan probes were customsynthesized by Applied Biosystems. Primers and probes for $U G T 1 A 1 * 6, U G T 1 A 1 * 27, U G T 1 A 1 * 60$, and $U G T 1 A 7 * 12$ were obtained from Applied Biosystems (TaqMan SNP Genotyping Assays). Reaction mixtures were loaded into 384-well plates and analyzed in an ABI Prism 7900HT Sequence Detection System (Applied Biosystems).

\subsection{Statistical Analysis}

Each nucleotide polymorphism was evaluated for the HardyWeinberg equilibrium, and by linkage disequilibrium (LD) analysis using Haploview 4.2 software (Massachusetts Institute of Technology, Cambridge, MA, USA; http://www. broadinstitute.org/scientific-community/science/programs/ medical-and-population-genetics/haploview/haploview). The Lewontin's coefficient $D^{\prime}$ and correlation coefficient, $r^{2}$, were calculated as measures of LD. The proportions of subjects with homozygous wild-type alleles or heterozygous or homozygous variant alleles were calculated with $95 \%$ Agresti-Coull confidence intervals (95\% CI).
Exon 1

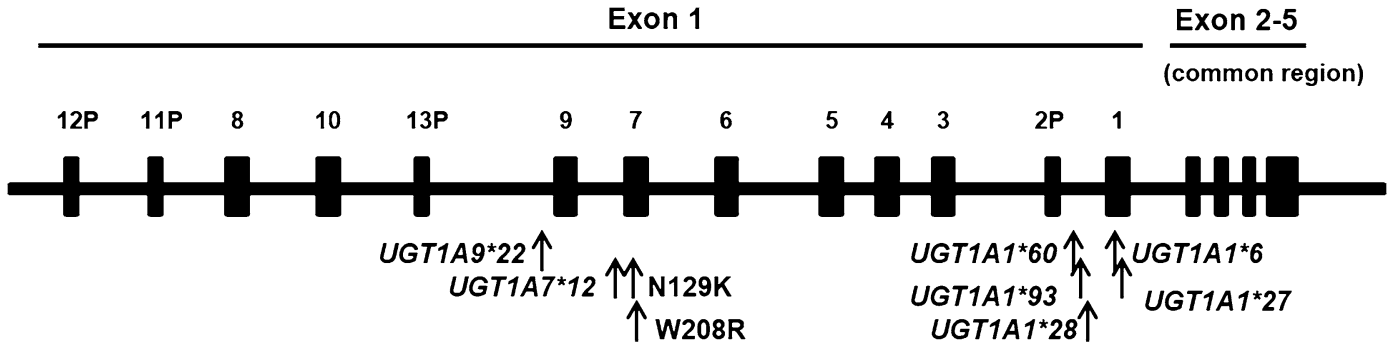

Fig. 1 Schematic illustration of the UGT1A gene showing the locations of polymorphisms investigated in the present study. 13P, 12P, 11P, and $2 \mathrm{P}$ represent pseudogenes present in exon 1. Exons 2-4 are common exons. The enzyme, UGT1A, is produced through splicing of exon 1 
Fisher's exact test with a two-sided significance level of 0.05 was used for comparing the areas. For a two-sided $95 \%$ CI for a binomial proportion whose true value is varied from 0.5 to 0.1 , a sample size of 50 yields a halfwidth of, at most, $14 \%$ in any situations of the true value. These analyses were performed using SAS v9.3 (SAS Institute Inc., Cary, NC, USA).

\section{Results}

\subsection{Baseline Characteristics, Hardy-Weinberg Equilibrium, and Linkage Disequilibrium}

The average age of the participants was 41.1 (range 19-78) years in Uzbekistan, and 39.9 (range 18-67) years in Japan. The 97 volunteers from Uzbekistan comprised 37 female and 60 males, while 125 of the 150 Japanese volunteers were female. As described previously [21], the Japanese volunteers were mainly recruited from nurses, which is an occupation traditionally chosen by women in Japan.

All of the UGT1A polymorphisms were in HardyWeinberg equilibrium $(P>0.05)$. Perfect linkages were observed between W208 and UGT1A7*12 in both the Uzbek and the Japanese populations (data not shown). UGT1A $1 * 28$ and UGT1A1*93 showed very strong linkage in the Uzbek population $\left(r^{2}=0.95, D^{\prime}=1.00\right)$ and they matched completely in the Japanese population (Fig. 2). Close linkage was also observed between $\mathrm{N} 129 \mathrm{~K}$ and $U G T 1 A 9 * 22$, both in the Uzbek $\left(r^{2}=0.94\right.$, $\left.D^{\prime}=1.00\right)$, and in the Japanese $\left(r^{2}=0.92, D^{\prime}=1.00\right)$ populations.

\subsection{Frequencies of UGT1A1 Polymorphisms}

Table 2 lists the frequencies of UGT1A1 polymorphisms, $U G T 1 A 1 * 6, * 28, * 60, * 27$, and *93. The two polymorphisms that have been extensively studied for their role in irinotecan metabolism, UGT1A1*28 and UGT1A1*6, showed different incidences in the Uzbek and Japanese populations. UGT1A1*28 showed a significantly higher incidence and $U G T 1 A 1 * 6$ showed a significantly lower incidence in the Uzbek and the Japanese populations $(P<0.01, P=0.012$, respectively). Neither $U G T 1 A 1 * 36$ (5TA repeat in the promoter region) nor UGT1Al*37 (8TA repeat in the promoter region) were identified among the Uzbek volunteers. Among the other UGT1A1 polymorphisms examined, $U G T 1 A * 27$ was very rare in both Uzbek and Japanese populations, occurring at a rate of 0.005 and 0.003 , respectively, and $U G T 1 A 1 * 60$ and $U G T 1 A 1 * 93$ were significantly more prevalent in the Uzbek population than in the Japanese population (both $P<0.01)$.
3.3 Frequencies of UGT1A7 and UGT1A9 Polymorphisms

Table 3 lists the frequencies of $U G T 1 A 7 * 3$ (N129K and W208R), UGT1A7*12, and UGT1A9*22. The Uzbek population had a significantly higher incidence of homozygous N129K than did the Japanese population $(P<0.01)$. However, the incidences of W208R and $U G T 1 A 7 * 12$ were not significantly different between the two populations; furthermore, W208R and UGT1A7*12 showed evidence of genetic linkage, which is reflected in their identical values in Table 3 . No Uzbek individual carrying heterozygous $U G T 1 A 7 * 1 / * 4$ or $* 3 / * 4$, or homozygous $U G T 1 A 7 * 4$ was detected. $U G T 1 A 7 * 1$ is less prevalent in Uzbekistan than in Japan $(P<0.01)$. $U G T 1 A 9 * 22$ was significantly less prevalent in the Uzbek population than in the Japanese population $(P<0.01)$.

\section{Discussion}

UGT1A is an essential enzyme for the elimination of numerous endogenous and exogenous compounds through glucuronidation [22]. Here, we analyzed the allele frequencies of several UGT1A polymorphisms in 97 healthy Uzbek volunteers and compared them with those of the Japanese population.

The polymorphism $U G T 1 A 1 * 28$ ([TA $]_{7}$ in the UGT1A1 promoter region) has been extensively investigated [23, 24], particularly in terms of inter-individual variability of irinotecan-induced gastrointestinal and hematological toxicity [5-12]. Because inactivation of the active form of irinotecan (SN-38) protects against severe irinotecan-related toxicity, decreased transcriptional activity of UGT1A1 due to $U G T 1 A 1 * 28$ is considered to be a risk factor for adverse reactions to irinotecan treatment. Here, we showed that the incidence of $U G T 1 A 1 * 28$ homozygotes in the Uzbek population was $9.3 \%$, which was significantly higher than that in the Japanese population that we studied previously [21]. In published reports, the incidence of UGT1A $1 * 28$ homozygotes is high in Europe (5-14.8\%), Africa (5.9-17.9\%), and India (12.8-19.3\%); and less frequent in East Asia and Japan (0-5.9 \%) [5-8, 25-31]; the allele frequency of $U G T 1 A 1 * 28$ shows a similar trend to the incidence of homozygotes (Table 4). Horsfall et al. [23] and Premawardhena et al. [24] reported further diversity in the numbers of TA repeats (i.e. $[\mathrm{TA}]_{5}$ termed $U G T 1 A 1 * 36$, and $[\mathrm{TA}]_{8}$ termed $\left.U G T 1 A 1 * 37\right)$ among individuals from Africa and those with varying degrees of African ancestry in North and Central America. $U G T 1 A 1 * 36$ and $U G T 1 A 1 * 37$ are also present in Caucasian and Indian populations at a very low rate [24, 30]; however, to our knowledge, they have not been detected in 


\begin{tabular}{|c|c|c|c|c|c|c|c|c|}
\hline & & & & ek popu & ation & & & \\
\hline & $U G T 1 A 1^{*} 6$ & UGT1A1*27 & UGT1A1*28 & UGT1A1*60 & UGT1A1*93 & N129K & W208R & UGT1A9* 22 \\
\hline UGT1A1*6 & & 1.00 & 1.00 & 1.00 & 1.00 & 1.00 & 1.00 & 0.55 \\
\hline UGT1A1*27 & 0.00 & & 1.00 & 1.00 & 1.00 & 1.00 & 1.00 & 1.00 \\
\hline UGT1A1*28 & 0.04 & 0.01 & & 1.00 & 1.00 & 0.22 & 0.39 & 0.21 \\
\hline UGT1A1*60 & 0.09 & 0.01 & 0.47 & & 1.00 & 0.48 & 0.34 & 0.45 \\
\hline UGT1A1*93 & 0.04 & 0.01 & 0.95 & 0.45 & & 0.17 & 0.39 & 0.16 \\
\hline $\mathrm{N} 129 \mathrm{~K}$ & 0.07 & 0.01 & 0.02 & 0.17 & 0.01 & & 1.00 & 1.00 \\
\hline W208R & 0.20 & 0.00 & 0.14 & 0.06 & 0.14 & 0.35 & & 0.91 \\
\hline UGT1A9* 22 & 0.02 & 0.01 & 0.02 & 0.15 & 0.01 & 0.94 & 0.31 & \\
\hline
\end{tabular}

\begin{tabular}{|c|c|c|c|c|c|c|c|c|}
\hline \multicolumn{9}{|c|}{ Japanese population } \\
\hline & UGT1A1*6 & UGT1A1*27 & UGT1A1*28 & UGT1A1*60 & UGT1A1*93 & N129K & W208R & UGT1A9* 22 \\
\hline UGT1A1*6 & & 1.00 & 0.97 & 1.00 & 0.97 & 0.85 & 0.89 & 0.78 \\
\hline UGT1A1*27 & 0.00 & & 1.00 & 1.00 & 1.00 & 1.00 & 1.00 & 1.00 \\
\hline UGT1A1*28 & 0.03 & 0.02 & & 1.00 & 1.00 & 0.53 & 0.52 & 0.55 \\
\hline UGT1A1*60 & 0.07 & 0.01 & 0.42 & & 1.00 & 0.68 & 0.22 & 0.70 \\
\hline UGT1A1*93 & 0.03 & 0.02 & 1.00 & 0.42 & & 0.53 & 0.52 & 0.55 \\
\hline N129K & 0.27 & 0.01 & 0.07 & 0.28 & 0.07 & & 1.00 & 1.00 \\
\hline W208R & 0.49 & 0.00 & 0.12 & 0.05 & 0.12 & 0.59 & & 0.89 \\
\hline UGT1A9* 22 & 0.25 & 0.01 & 0.08 & 0.32 & 0.08 & 0.92 & 0.51 & \\
\hline & & $0.8-1$ & & $0.8-1$ & & & & \\
\hline & & $0.6-0.8$ & & $0.6-0.8$ & & & & \\
\hline & $r^{2}$ & $0.4-0.6$ & $\mathrm{D}^{\prime}$ & $0.4-0.6$ & & & & \\
\hline & & $0.2-0.4$ & & $0.2-0.4$ & & & & \\
\hline & & $0-0.2$ & & $0-0.2$ & & & & \\
\hline
\end{tabular}

Fig. 2 Linkage disequilibrium analysis for UGT1A1, 1A7, and $1 A 9$ polymorphisms. Strong linkages are shown between $U G T 1 A 1 * 28$ and $U G T 1 A 1 * 93$, and between $\mathrm{N} 129 \mathrm{~K}$ and $U G T 1 A 1 * 93$, respectively, in both Uzbek and Japanese populations. Each square is colored according to the value of $D^{\prime}$ (upper brown) and $r^{2}$ (lower blue)

Japan. Neither $U G T 1 A 1 * 36$ nor $U G T 1 A 1 * 37$ were identified among the 97 Uzbek volunteers.

The polymorphism UGT1A1*6 has also been extensively studied and has been shown to be associated with decreased irinotecan metabolism [19]. The current study showed the rates of heterozygotes and homozygotes for $U G T 1 A 1 * 6$ in Uzbekistan were 13.4 and $2.1 \%$, respectively, which was significantly lower than the equivalent rates in the Japanese population we studied previously [21]. In a previous study, only two heterozygotes among 150 Caucasians and no individuals among 150 African-Americans were found to carry $U G T 1 A 1 * 6$ [25]. The incidence of $U G T 1 A 1 * 6$ polymorphisms in the Uzbek population was more frequent that that previously reported in Caucasian and African populations (Table 4).

The variant $686 \mathrm{C}>\mathrm{A}(U G T 1 A 1 * 27)$ is a very rare polymorphism that is associated with a significant reduction in UGT1A activity in vitro [19]. No UGT1A1*27 allele was detected in 150 Caucasian or 150 African-American healthy volunteers [25], or in more than 300 Indian healthy volunteers [30, 31] (Table 4). In contrast, studies from Japan identified heterozygous UGT1Al*27 in $2.6 \%$ of Japanese colorectal cancer patients [5], in $0.7 \%$ of Japanese or African-American healthy volunteers [21, 25], and in $2.3 \%$ of a mixed population of Japanese arrhythmic patients and cancer patients [26]. The current study 
Table 2 UGT1A1 polymorphisms

\begin{tabular}{|c|c|c|c|c|}
\hline & \multicolumn{3}{|c|}{$U G T 1 A 1 * 6(P=0.012)$} & \multirow[t]{2}{*}{ Allele frequency of $U G T 1 A 1 * 6$} \\
\hline & $\mathrm{G} / \mathrm{G}$ & G/A & $\mathrm{A} / \mathrm{A}$ & \\
\hline Uzbekistan & $82(85,79-93)$ & $13(13,8-22)$ & $2(2,0-8)$ & 0.09 \\
\hline Japan & $103(69,61-76)$ & $43(29,22-36)$ & $4(3,0-7)$ & 0.17 \\
\hline \multirow[t]{3}{*}{$P$ value } & 0.007 & 0.005 & 1.000 & \\
\hline & \multicolumn{3}{|c|}{$U G T 1 A 1 * 27(P=0.394)$} & \multirow[t]{2}{*}{ Allele frequency of UGT $1 \mathrm{~A} 1 * 27$} \\
\hline & $\mathrm{C} / \mathrm{C}$ & $\mathrm{C} / \mathrm{A}$ & $\mathrm{A} / \mathrm{A}$ & \\
\hline Uzbekistan & $96(99,94-100)$ & $1(1,0-6)$ & $0(0,0-3)$ & 0.005 \\
\hline Japan & $149(99,96-100)$ & $1(1,0-4)$ & $0(0,0-2)$ & 0.003 \\
\hline \multirow[t]{3}{*}{$P$ value } & 0.394 & 0.394 & - & \\
\hline & \multicolumn{3}{|c|}{$U G T 1 A 1 * 28(P<0.01)$} & \multirow[t]{2}{*}{ Allele frequency of $U G T 1 A 1 * 28$} \\
\hline & $(\mathrm{TA})_{6} /(\mathrm{TA})_{6}$ & $(\mathrm{TA})_{6} /(\mathrm{TA})_{7}$ & $(\mathrm{TA})_{7} /(\mathrm{TA})_{7}$ & \\
\hline Uzbekistan & $45(46,37-56)$ & $43(44,35-54)$ & $9(9,5-17)$ & 0.31 \\
\hline Japan & $115(77,69-83)$ & $33(22,16-29)$ & $2(1,0-5)$ & 0.12 \\
\hline \multirow[t]{3}{*}{$P$ value } & $<0.01$ & $<0.01$ & 0.008 & \\
\hline & \multicolumn{3}{|c|}{$U G T 1 A 1 * 60(P<0.01)$} & \multirow[t]{2}{*}{ Allele frequency of UGT $1 \mathrm{~A} 1 * 60$} \\
\hline & $\mathrm{T} / \mathrm{T}$ & $\mathrm{T} / \mathrm{G}$ & $\mathrm{G} / \mathrm{G}$ & \\
\hline Uzbekistan & $25(26,18-35)$ & $48(49,40-59)$ & $24(25,17-34)$ & 0.50 \\
\hline Japan & $79(53,45-60)$ & $66(44,36-52)$ & $5(3,1-8)$ & 0.25 \\
\hline \multirow[t]{3}{*}{$P$ value } & $<0.01$ & 0.434 & $<0.01$ & \\
\hline & \multicolumn{3}{|c|}{$U G T 1 A 1 * 93(P<0.01)$} & \multirow[t]{2}{*}{ Allele frequency of UGT $1 \mathrm{~A} 1 * 93$} \\
\hline & $\mathrm{G} / \mathrm{G}$ & G/A & $\mathrm{A} / \mathrm{A}$ & \\
\hline Uzbekistan & $46(47,38-57)$ & $43(44,35-54)$ & $8(8,4-16)$ & 0.30 \\
\hline Japan & $115(77,69-83)$ & $33(22,16-29)$ & $2(1,0-5)$ & 0.12 \\
\hline$P$ value & $<0.01$ & $<0.01$ & 0.016 & \\
\hline
\end{tabular}

Polymorphisms of UGT1A1 are shown. For each genotype, the values represent the number of subjects (percentage of subjects, $95 \% \mathrm{CI}$ ). Heterozygous and homozygous $U G T 1 A 1 * 28, * 60$, and $* 93$ were observed significantly more frequently in the Uzbek population than in the Japanese population. In contrast, heterozygous and homozygous $U G T 1 A 1 * 6$ were significantly less prevalent in the Uzbek population than in the Japanese population. The occurrence of $U T G 1 A 1 * 27$ was rare in both populations

demonstrated that the incidence of $U G T 1 A 1 * 27$ heterozygotes was also low in the Uzbek population (1 of 97 individuals).

UGT1A $1 * 60$ and UGT1A*93 are the polymorphisms that result in reduced UGT1A1 enzyme efficacy and may be related to the hematological toxicity observed after irinotecan treatment $[8,32]$. The allele frequency of UGT1A1*60 in the Uzbek population (0.5) was higher than that in various reports of the Japanese population (0.23-0.26), including our previous study. The frequency was similar to that reported for Caucasian (0.44-0.62) and Indian (0.43) populations, and lower than that reported for the African population (0.85) (Table 4). Heterozygous or homozygous UGT1A1*93 was observed significantly more frequently in the Uzbek population than in the Japanese population that we studied previously [21]. In a small study of the Chinese population [27], UGT1A1*93 was detected at a frequency of 0.12 , which is similar to that reported in various studies of the Japanese population, including our previous study. In contrast, UGT1A1*93 is relatively common in Europe, Africa, India, and Uzbekistan.

$U G T 1 A 9 * 22$ is characterized by a one-base thymidine insertion in the promoter region of UGT1A9, which increases the UGT1A9 levels and causes a higher clearance rate of $\mathrm{SN}-38 \mathrm{G}$ than that observed for UGT1A9*1 [33]. Our previous study [21] revealed that the allele frequency of $U G T 1 A 9 * 22$ in healthy Japanese volunteers was 0.66 , which is comparable to that in Japanese colorectal cancer patients (0.54-0.66) [9, 33, 34]. A study of colorectal cancer patients who were mainly of Caucasian origin 
Table 3 UGT1A7 and UGT1A9 polymorphisms

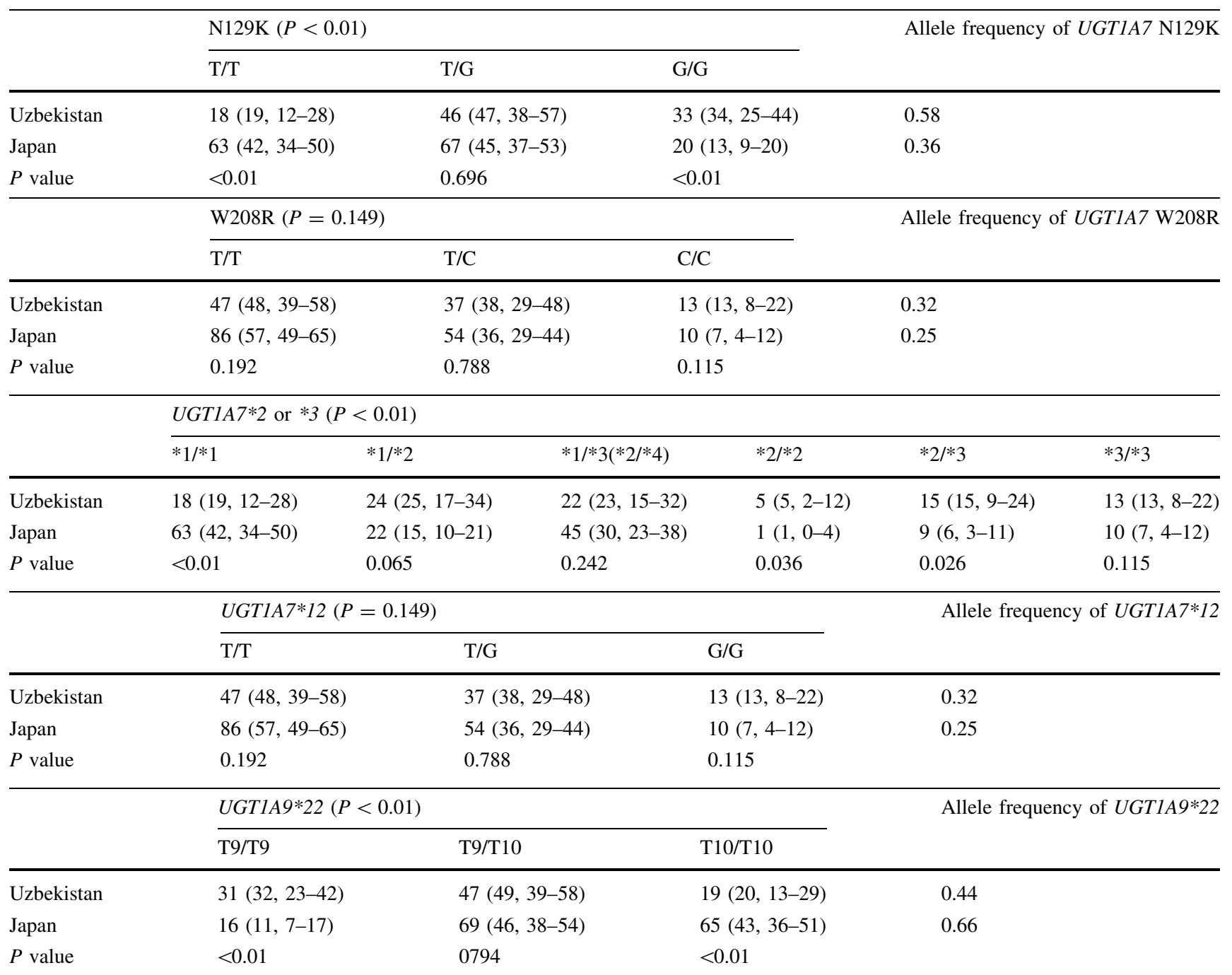

For each genotype, the values represent the number of subjects (percentage of subjects, $95 \% \mathrm{CI}$ ). The occurrence of N129 alone is termed $U G T 1 A 7 * 2$, and the occurrence of $\mathrm{W} 208$ alone is termed $U G T 1 A 7 * 4$, whereas co-occurrence of N129K and W208R is termed $U G T 1 A 7 * 3$. In the case of heterozygous $\mathrm{N} 129 \mathrm{~K}$ and heterozygous W208R, the possible genotypes are $U G T 1 A 7 * 1 / * 3$ and $* 2 / * 4$; however, because $U G T 1 A 7 * 4$ is known to be quite rare in non-Uzbek populations, the statistical analysis was performed on the assumption that all the genotypes were $U G T 1 A 7 * 1 / * 3$

reported a $U G T 1 A 9 * 22$ allele frequency of $0.4[8,35]$, which is similar to that observed here for the healthy Uzbek volunteers.

In the present study, no Uzbek individual carrying $U G T 1 A 7 * 1 / * 4, * 3 / * 4$, or $* 4 / * 4$ was detected. The experimental methods used in the current study cannot directly determine $U G T 1 A 7 * 1, * 2$, *3, or $* 4$. Therefore, when both heterozygous N129K and heterozygous W208R were detected in the same individual, the possible genotypes were $U G T 1 A 7 * 1 / * 3$ or $* 2 / * 4$. However, because the frequency of $U G T 1 A 7 * 4$ is known to be quite rare among Caucasian [17, 36], Japanese [9, 26, 37], and Chinese [38] populations, we assumed that the only possible genotype was $U G T 1 A 7 * 1 / * 3$. Accordingly, the allele frequency of
$U G T 1 A 7 * 1$ in the Uzbek population was lower than that reported for East Asia and Japan [9, 26, 38], slightly higher than that reported for India [40], and similar to that reported for both Africa and Europe [12, 32, 41]. UGT1A7*3 is associated with reduced enzymatic activity compared with the wild-type [42], and might be related to the irinotecan toxicity in colorectal cancer patients [20, 34].

The relationship between $U G T 1 A$ polymorphisms and irinotecan-induced toxicities remains controversial. For instance, several early studies reported a strong association between $U G T 1 A 1 * 28$ with severe (grade 3 or 4 ) toxicity in Japanese [5, 6, 11] and Caucasian colorectal patients [10]; however, another study found that UGTIA $1 * 28$ had little or no effect on the rate of adverse effects in such patients 
Table 4 Allele frequency of UGT1A polymorphisms in different ethnic groups

\begin{tabular}{|c|c|c|c|c|c|c|}
\hline \multirow[b]{2}{*}{ Reference } & \multicolumn{6}{|l|}{ Origin } \\
\hline & $\begin{array}{l}\text { Africa } \\
23-25,32, \\
41\end{array}$ & $\begin{array}{l}\text { Europe } \\
7,8,17,23-25,28,32,35 \\
36,41\end{array}$ & $\begin{array}{l}\text { Uzbekistan } \\
\text { Present } \\
\text { study }\end{array}$ & $\begin{array}{l}\text { India } \\
24,30,31 \\
40\end{array}$ & $\begin{array}{l}\text { East Asia } \\
27,29,31,32,38, \\
39\end{array}$ & $\begin{array}{l}\text { Japan } \\
5,6,9,12,13,21,25,26,33 \text {, } \\
34,37\end{array}$ \\
\hline$U G T 1 A 1 * 6$ & 0 & $0.007-0.01$ & 0.09 & $0.066-0.16$ & $0.13-0.24$ & $0.14-0.23$ \\
\hline$U G T 1 A 1 * 27$ & 0 & 0 & 0.005 & 0 & $0.015-0.02$ & 0.003 \\
\hline$U G T 1 A 1 * 28$ & $0.26-0.4$ & $0.23-0.38$ & 0.31 & $0.28-0.41$ & $0.07-0.17$ & $0.04-0.14$ \\
\hline UGT1A1*60 & 0.85 & $0.44-0.62$ & 0.5 & 0.43 & $0.235-0.34$ & $0.23-0.26$ \\
\hline UGT1A1*93 & 0.29 & $0.23-0.35$ & 0.3 & 0.35 & 0.12 & 0.12 \\
\hline$U G T 1 A 7 * 1$ & 0.38 & $0.34-0.43$ & 0.422 & 0.26 & $0.58-0.63$ & $0.59-0.65$ \\
\hline$U G T 1 A 7 * 2$ & 0.39 & $0.24-0.28$ & 0.252 & 0.36 & $0.22-0.27$ & $0.1-0.14$ \\
\hline$U G T 1 A 7 * 3$ & 0.23 & $0.31-0.35$ & 0.325 & 0.36 & 0.15 & $0.21-0.29$ \\
\hline$U G T 1 A 7 * 4$ & 0.01 & $0-0.019$ & 0 & 0.032 & 0 & $0-0.03$ \\
\hline$U G T 1 A 9 * 22$ & 0.44 & $0.39-0.41$ & 0.44 & - & 0.42 & $0.6-0.66$ \\
\hline
\end{tabular}

Different ethnic groups have different allele frequencies of UGT1A polymorphisms. Note that individual cohorts contributing to the ethnic group data comprised healthy volunteers or cancer patients or both. Europe includes individuals from several different European countries and Caucasians from non-European countries. East Asia includes China and Korea. All allele frequencies obtained from our previous study of the Japanese population are within the range of reported studies (Tables 2, 3)

$[7,8,27]$. Inconsistent patient responses to irinotecan imply that factors such as age, organ function, concomitant therapy [3, 4], and dose of irinotecan [7] might modulate the therapeutic and adverse effects of this drug. However, the variable responses might also be explained by the synergic effect of $U G T 1 A I * 28$ and other UGTIA polymorphisms, such as $U G T 1 A{ }^{*} 6$ and $U G T 1 A 7 * 3[12,13$, $20,28]$. Our finding that there is a significantly different distribution of UGT1A polymorphisms in Uzbekistan and Japan strengthens this hypothesis, and provides further evidence that extensive studies of the relationships between UGT1A haplotypes and the risk of irinotecan toxicity would be worthwhile.

One limitation of this study was that the number of the Uzbek healthy volunteers examined was small. Thus, the rate of detection of rare polymorphisms, such as $U G T 1 A 1 * 36, U G T 1 A 1 * 37$, and $U G T 1 A 1 * 27$, might not be representative of the whole Uzbek population. However, for other polymorphisms, the numbers of volunteers was sufficient to show very strong statistical differences between the Uzbek population and the Japanese population. Another limitation of the study was that a statistical comparison of the frequency of UGTIA polymorphisms in the Uzbek population and other populations that were studied using different genotyping methods was not possible. Our ongoing study of various ethnic groups from Asia to Europe will allow such direct comparisons and may clarify the movement of people throughout history [21].

LD analysis in the present study revealed strong linkage between some UGT1A genotypes. Recently, strong linkage between $\mathrm{N} 129 \mathrm{~K}$ and $U G T 1 A 9 * 22$, as we have observed in Uzbek and Japanese populations, was also reported in a
Caucasian population [8]. In contrast, the linkage between $U G T 1 A 1 * 28$ and $U G T 1 A 1 * 93$ was stronger in both Uzbek and Japanese populations $\left(r^{2}=0.94\right.$ and 0.92 , respectively) than in a Caucasian population $\left(r^{2}=0.6782\right)$ [8]. This suggests that the difference in haplotype frequencies between different populations reflects both genotype (polymorphism) frequencies and the strength of LD. It is also plausible that the different strength of linkage is one of the reasons for the inconsistency observed between the adverse effects of irinotecan and the presence of UGTIA polymorphisms in treated patients. Thus, further investigation is required of UGTIA LD and haplotypes.

Our results revealed that $U G T 1 A 1 * 28$ is more frequent in the Uzbek population than in the Japanese population, and is present at a similar rate to that reported for Caucasian and African populations. In contrast, UGTIAl*6 is less prevalent in the Uzbek population than in the Japanese population, but has a higher incidence than previous reports in Caucasians. Although UGT1Al $* 27$ has not been reported in African and Caucasian populations, it was identified in a single Uzbek volunteer. UGTIAI*60 and $* 93$ were detected more frequently in the Uzbek population than in the Japanese population, and the rate was similar to that reported for Caucasians. Finally, UGT1A9*22 was identified in the Uzbek population at a lower rate than that in the Japanese population. These findings confirm the inter-ethnic diversity of polymorphisms in UGTIA and lead us to speculate that the Uzbekistan population has genetic characteristic between those of East Asia and European countries, consistent with its geographical location (Table 4). We anticipate that further comprehensive studies revealing the relationship between UGTIAl 
polymorphisms and the risk of irinotecan-induced toxicity will facilitate individual treatment option decisions.

Acknowledgments and Disclosures This study was supported in part by a non-profit organization, Epidemiological and Clinical Research Information Network (ECRIN), as well as a Grant-in-Aid for Scientific Research of the Ministry of Education, Science, Sports and Culture of Japan (project No. 21591725 and 19591545). The authors have no conflicts of interest that are directly relevant to the content of this article.

Author contributions All authors equally contributed to this study.

Open Access This article is distributed under the terms of the Creative Commons Attribution Noncommercial License which permits any noncommercial use, distribution, and reproduction in any medium, provided the original author(s) and the source are credited.

\section{References}

1. Douillard JY, Cunningham D, Roth AD, Navarro M, James RD, Karasek P, Jandik P, Iveson T, Carmichael J, Alakl M, Gruia G, Awad L, Rougier P. Irinotecan combined with fluorouracil compared with fluorouracil alone as first-line treatment for metastatic colorectal cancer: a multicentre randomised trial. Lancet. 2000;355:1041-7.

2. Saltz LB, Cox JV, Blanke C, Rosen LS, Fehrenbacher L, Moore MJ, Maroun JA, Ackland SP, Locker PK, Pirotta N, Elfring GL, Miller LL. Irinotecan plus fluorouracil and leucovorin for metastatic colorectal cancer. Irinotecan Study Group. N Engl J Med. 2000;343:905-14.

3. Dranitsaris G, Shah A, Spirovski B, Vincent M. Severe diarrhea in patients with advanced-stage colorectal cancer receiving FOLFOX or FOLFIRI chemotherapy: the development of a risk prediction tool. Clin Colorectal Cancer. 2007;6:367-73.

4. Shiozawa T, Tadokoro J, Fujiki T, Fujino K, Kakihata K, Masatani S, Morita S, Gemma A, Boku N. Risk factors for severe adverse effects and treatment-related deaths in Japanese patients treated with irinotecan-based chemotherapy: a postmarketing survey. Jpn J Clin Oncol. 2013;43:483-91.

5. Ando Y, Saka H, Ando M, Sawa T, Muro K, Ueoka H, Yokoyama A, Saitoh S, Shimokata K, Hasegawa Y. Polymorphisms of UDP-glucuronosyltransferase gene and irinotecan toxicity: a pharmacogenetic analysis. Cancer Res. 2000;60:6921-6.

6. Okuyama Y, Hazama S, Nozawa H, Kobayashi M, Takahashi K, Fujikawa K, Kato T, Nagata N, Kimura H, Oba K, Sakamoto J, Mishima H. Prospective phase II study of FOLFIRI for mCRC in Japan, including the analysis of UGT1A1 28/6 polymorphisms. Jpn J Clin Oncol. 2011;41:477-82.

7. Toffoli G, Cecchin E, Corona G, Russo A, Buonadonna A, D'Andrea M, Pasetto LM, Pessa S, Errante D, De Pangher V, Giusto M, Medici M, Gaion F, Sandri P, Galligioni E, Bonura S, Boccalon M, Biason P, Frustaci S. The role of UGT1A1*28 polymorphism in the pharmacodynamics and pharmacokinetics of irinotecan in patients with metastatic colorectal cancer. J Clin Oncol. 2006;24:3061-8.

8. Cecchin E, Innocenti F, D'Andrea M, Corona G, De Mattia E, Biason P, Buonadonna A, Toffoli G. Predictive role of the UGT1A1, UGT1A7, and UGT1A9 genetic variants and their haplotypes on the outcome of metastatic colorectal cancer patients treated with fluorouracil, leucovorin, and irinotecan. J Clin Oncol. 2009;27:2457-65.
9. Inoue K, Sonobe M, Kawamura Y, Etoh T, Takagi M, Matsumura T, Kikuyama M, Kimura M, Minami S, Utsuki H, Yamazaki T, Suzuki T, Tsuji D, Hayashi H, Itoh K. Polymorphisms of the UDP-glucuronosyl transferase $1 \mathrm{~A}$ Genes are associated with adverse events in cancer patients receiving irinotecan-based chemotherapy. Tohoku J Exp Med. 2013;229:107-14.

10. Iyer L, Das S, Janisch L, Wen M, Ramírez J, Karrison T, Fleming GF, Vokes EE, Schilsky RL, Ratain MJ. UGT1A1*28 polymorphism as a determinant of irinotecan disposition and toxicity. Pharmacogenomics J. 2002;2:43-7.

11. Hazama S, Nagashima A, Kondo H, Yoshida S, Shimizu R, Araki A, Yoshino S, Okayama N, Hinoda Y, OkaPhase M. Phase I, study of irinotecan and doxifluridine for metastatic colorectal cancer focusing on the UGT1A $1 * 28$ polymorphism. Cancer Sci. 2010;101:722-7.

12. Araki K, Fujita K, Ando Y, Nagashima F, Yamamoto W, Endo H, Miya T, Kodama K, Narabayashi M, Sasaki Y. Pharmacogenetic impact of polymorphisms in the coding region of the UGT1A1 gene on SN-38 glucuronidation in Japanese patients with cancer. Cancer Sci. 2006;97:1255-9.

13. Onoue M, Terada T, Kobayashi M, Katsura T, Matsumoto S, Yanagihara K, Nishimura T, Kanai M, Teramukai S, Shimizu A, Fukushima M, Inui K. UGT1A1*6 polymorphism is most predictive of severe neutropenia induced by irinotecan in Japanese cancer patients. Int J Clin Oncol. 2009;14:136-42.

14. Kawato Y, Aonuma M, Hirota Y, Kuga H, Sato K. Intracellular roles of SN-38, a metabolite of the camptothecin derivative CPT11 , in the antitumor effect of CPT-11. Cancer Res. 1991;51:4187-91.

15. Gupta E, Lestingi TM, Mick R, Ramirez J, Vokes EE, Ratain MJ. Metabolic fate of irinotecan in humans: correlation of glucuronidation with diarrhea. Cancer Res. 1994;54:3723-5.

16. Iyer L, King CD, Whitington PF, Green MD, Roy SK, Tephly TR, Coffman BL, Ratain MJ. Genetic predisposition to the metabolism of irinotecan (CPT-11). Role of uridine diphosphate glucuronosyltransferase isoform 1A1 in the glucuronidation of its active metabolite (SN-38) in human liver microsomes. J Clin Invest. 1998;101:847-54.

17. Pacheco PR, Brilhante MJ, Ballart C, Sigalat F, Polena H, Cabral R, Branco CC, Mota-Vieira L. UGT1A1, UGT1A6 and UGT1A7 genetic analysis: repercussion for irinotecan pharmacogenetics in the São Miguel Island Population (Azores, Portugal). Mol Diagn Ther. 2009;13:261-8.

18. Bosma PJ, Chowdhury JR, Bakker C, Gantla S, de Boer A, Oostra BA, Lindhout D, Tytgat GN, Jansen PL, Oude Elferink RP, Chowdhury NR. The genetic basis of the reduced expression of bilirubin UDP-glucuronosyltransferase 1 in Gilbert's syndrome. N Engl J Med. 1995;333:1171-5.

19. Gagné JF, Montminy V, Belanger P, Journault K, Gaucher G, Guillemette C. Common human UGT1A polymorphisms and the altered metabolism of irinotecan active metabolite 7-ethyl-10hydroxycamptothecin (SN-38). Mol Pharmacol. 2002;62:608-17.

20. Hazama S, Mishima H, Tsunedomi R, Okuyama Y, Kato T, Takahashi KI, Nozawa H, Ando H, Kobayashi M, Takemoto H, Nagata N, Kanekiyo S, Inoue Y, Hamamoto Y, Fujita Y, Hinoda Y, Okayama N, Oba K, Sakamoto JI, Oka M. UGT1A1*6, $1 \mathrm{~A} 7 * 3$, and $1 \mathrm{~A} 9 * 22$ genotypes predict severe neutropenia in FOLFIRI-treated metastatic colorectal cancer in two prospective studies in Japan. Cancer Sci. 2013 (Epub ahead of print).

21. Kobayashi M, Hazama S, Takahashi K, Oba K, Okayama N, Nishioka M, Hinoda Y, Oka M, Okamoto K, Maeda H, Nakamura $\mathrm{D}$, Sakamoto J, Mishima H. Is there diversity among UGT1A1 polymorphism in Japan? World J Gastrointest Oncol. 2012;4:170-5.

22. Clarke DJ, Burchell B. The Uridine diphosphate glucronosyltransferase multigene families: function and regulation. In: 
Kaufmann FC, editor. Handbook of experimental pharmacology. Berlin: Springer; 1994. p. 3-43.

23. Horsfall LJ, Zeitlyn D, Tarekegn A, Bekele E, Thomas MG, Bradman N, Swallow DM. Prevalence of clinically relevant UGT1A alleles and haplotypes in African populations. Ann Hum Genet. 2011;75:236-46.

24. Premawardhena A, Fisher CA, Liu YT, Verma IC, de Silva S, Arambepola M, Clegg JB, Weatherall DJ. The global distribution of length polymorphisms of the promoters of the glucuronosyltransferase 1 gene (UGT1A1): hematologic and evolutionary implications. Blood Cells Mol Dis. 2003;31:98-101.

25. Kaniwa N, Kurose K, Jinno H, Tanaka-Kagawa T, Saito Y, Saeki M, Sawada J, Tohkin M, Hasegawa R. Racial variability in haplotype frequencies of UGT1A1 and glucuronidation activity of a novel single nucleotide polymorphism 686C $>\mathrm{T}$ (P229L) found in an African-American. Drug Metab Dispos. 2005;33:458-65.

26. Saeki M, Saito Y, Jinno H, Sai K, Ozawa S, Kurose K, Kaniwa N, Komamura K, Kotake T, Morishita H, Kamakura S, Kitakaze M, Tomoike H, Shirao K, Tamura T, Yamamoto N, Kunitoh H, Hamaguchi T, Yoshida T, Kubota K, Ohtsu A, Muto M, Minami H, Saijo N, Kamatani N, Sawada JI. Haplotype structures of the UGT1A gene complex in a Japanese population. Pharmacogenomics J. 2006;6:63-75.

27. Zhang A, Xing Q, Qin S, Du J, Wang L, Yu L, Li X, Xu L, Xu M, Feng G, He L. Intra-ethnic differences in genetic variants of the UGT-glucuronosyltransferase 1A1 gene in Chinese populations. Pharmacogenomics J. 2007;7:333-8.

28. Lamas MJ, Duran G, Balboa E, Bernardes B, Candamio S, Vidal Y, Mosquera A, Giraldez JM, Lopez R, Carracedo A, Barros F. The value of genetic polymorphisms to predict toxicity in metastatic colorectal patients with irinotecan-based regimens. Cancer Chemother Pharmacol. 2012;69:1591-9.

29. Han JY, Lim HS, Shin ES, Yoo YK, Park YH, Lee JE, Jang IJ, Lee DH, Lee JS. Comprehensive analysis of UGT1A polymorphisms predictive for pharmacokinetics and treatment outcome in patients with non-small-cell lung cancer treated with irinotecan and cisplatin. J Clin Oncol. 2006;24:2237-44.

30. D'Silva S, Colah RB, Ghosh K, Mukherjee MB. UDP-glucuronosyltransferase 1A1 (UGT1A1) gene haplotypes and their effect on serum bilirubin concentration in healthy Indian adults. Gene. 2013;513:36-9.

31. Teh LK, Hashim H, Zakaria ZA, Salleh MZ. Polymorphisms of UGT1A $1 * 6$, UGT1A $1 * 27 \&$ UGT1A $1 * 28$ in three major ethnic groups from Malaysia. Indian J Med Res. 2012;136:249-59.

32. Innocenti F, Kroetz DL, Schuetz E, Dolan ME, Ramírez J, Relling M, Chen P, Das S, Rosner GL, Ratain MJ. Comprehensive pharmacogenetic analysis of irinotecan neutropenia and pharmacokinetics. J Clin Oncol. 2009;1(27):2604-14.

33. Yamanaka H, Nakajima M, Katoh M, Hara Y, Tachibana $O$, Yamashita J, McLeod HL, Yokoi T. A novel polymorphism in the promoter region of human UGT1A9 gene (UGT1A9*22) and its effects on the transcriptional activity. Pharmacogenetics. 2004; $14: 329-32$.

34. Fujita K, Ando Y, Nagashima F, Yamamoto W, Eodo H, Araki K, Kodama K, Miya T, Narabayashi M, Sasaki Y. Genetic linkage of UGT1A7 and UGT1A9 polymorphisms to UGT1A1*6 is associated with reduced activity for SN-38 in Japanese patients with cancer. Cancer Chemother Pharmacol. 2007;60:515-22.

35. Carlini LE, Meropol NJ, Bever J, Andria ML, Hill T, Gold P, Rogatko A, Wang H, Blanchard RL. UGT1A7 and UGT1A9 polymorphisms predict response and toxicity in colorectal cancer patients treated with capecitabine/irinotecan. Clin Cancer Res. 2005;11:1226-36.

36. Köhle C, Möhrle B, Münzel PA, Schwab M, Wernet D, Badary OA, Bock KW. Frequent co-occurrence of the TATA box mutation associated with Gilbert's syndrome (UGT1A1*28) with other polymorphisms of the UDP-glucuronosyltransferase-1 locus (UGT1A6*2 and UGT1A7*3) in Caucasians and Egyptians. Biochem Pharmacol. 2003;65:1521-7.

37. Araki J, Kobayashi Y, Iwasa M, Urawa N, Gabazza EC, Taguchi O, Kaito M, Adachi Y. Polymorphism of UDP-glucuronosyltransferase 1A7 gene: a possible new risk factor for lung cancer. Eur J Cancer. 2005;41:2360-5.

38. Huang MJ, Yang SS, Lin MS, Huang CS. Polymorphisms of uridine-diphosphoglucuronosyltransferase 1A7 gene in Taiwan Chinese. World J Gastroenterol. 2005;11:797-802.

39. Tang KS, Chiu HF, Chen HH, Eng HL, Tsai CJ, Teng HC, Huang CS. Link between colorectal cancer and polymorphisms in the uridine-diphosphoglucuronosyltransferase 1A7 and 1A1 genes. World J Gastroenterol. 2005;11:3250-4.

40. Sharma R, Ahuja M, Panda NK, Khullar M. Interactions among genetic variants in tobacco metabolizing genes and smoking are associated with head and neck cancer susceptibility in North Indians. DNA Cell Biol. 2011;30:611-6.

41. Zheng Z, Park JY, Guillemette C, Schantz SP, Lazarus P. Tobacco carcinogen-detoxifying enzyme UGT1A7 and its association with orolaryngeal cancer risk. J Natl Cancer Inst. 2001;93:1411-8.

42. Strassburg CP, Strassburg A, Nguyen N, Li Q, Manns MP, Tukey RH. Regulation and function of family 1 and family 2 UDPglucuronosyltransferase genes (UGT1A, UGT2B) in human oesophagus. Biochem J. 1999;338:489-98. 